\title{
Histopathological Features of MRI-Invisible Regions of Prostate Cancer Lesions
}

van Houdt PJ ${ }^{1}$, Ghobadi $\mathrm{G}^{1}$, Schoots $\mathrm{IG}^{2,3}$, Heijmink SWTPJ ${ }^{2}$, de Jong $\mathrm{J}^{4}$, van der Poel $\mathrm{HG}^{5}$, Pos $\mathrm{FJ}^{1}$, Rylander $\mathrm{S}^{6}$, Bentzen $\mathrm{L}^{7}$, Haustermans $\mathrm{K}^{8}$, van der Heide $\mathrm{UA}^{1}$.

1 Department of Radiation Oncology, the Netherlands Cancer Institute, Amsterdam, The Netherlands.

2 Department of Radiology, the Netherlands Cancer Institute, Amsterdam, The Netherlands.

3 Department of Radiology and Nuclear Medicine, Erasmus University Medical Center, Rotterdam, The Netherlands.

4 Department of Pathology, the Netherlands Cancer Institute, Amsterdam, The Netherlands.

5 Department of Urology, the Netherlands Cancer Institute, Amsterdam, The Netherlands.

6 Department of Medical Physics, Aarhus University Hospital, Aarhus, Denmark.

7 Department of Oncology, Aarhus University Hospital, Aarhus, Denmark.

8 Department of Radiation Oncology, University Hospitals Leuven, Leuven, Belgium. 


\section{ABSTRACT}

\section{BACKGROUND:}

Previous studies have reported tumor volume underestimation with multiparametric (mp)MRI in prostate cancer diagnosis.

\section{PURPOSE:}

To investigate why some parts of lesions are not visible on mpMRI by comparing their histopathology features to those of visible regions.

\section{STUDY TYPE:}

Retrospective.

\section{POPULATION:}

Thirty-four patients with biopsy-proven prostate cancer scheduled for prostatectomy (median 68.7 years).

\section{FIELD STRENGTH/SEQUENCE:}

$T_{2}$-weighted, diffusion-weighted imaging, $T_{2}$ mapping, and dynamic contrast-enhanced MRI on two $3 \mathrm{~T}$ systems and one $1.5 \mathrm{~T}$ system.

\section{ASSESSMENT:}

Two readers delineated suspicious lesions on mpMRI. A pathologist delineated the lesions on histopathology. A patient-customized mold enabled the registration of histopathology and MRI. On histopathology we identified mpMRI visible and invisible lesions. Subsequently, within the visible lesions we identified regions that were visible and regions that were invisible on mpMRI. For each lesion and region the following characteristics were determined: size, location, International Society of Urological Pathology (ISUP) grade, and Gleason subpatterns (density [dense/intermediate], tumor morphology [homogeneous/heterogeneous], cribriform growth [yes/no]). 


\section{STATISTICAL TESTS:}

With generalized linear mixed-effect modeling we investigated which features explain why a lesion or a region was invisible on MRI. We compared imaging values $\left(T_{2}, A D C\right.$, and $\left.K^{\text {trans }}\right)$ for these features with one-way analysis of variance (ANOVA).

\section{RESULTS:}

Small, anterior, and ISUP grade 1-2 lesions $(n=34)$ were missed more frequent than large, posterior, ISUP grade $\geq 3$ lesions $(n=35)$. Invisible regions on mpMRI had lower tumor density, heterogeneous tumor morphology, and were located in the transition zone. Both $\mathrm{T}_{2}$ and $A D C$ values were higher in "intermediate" compared with "dense" regions $(P=0.002$ and $<0.001)$ and in regions with heterogeneous compared with homogeneous morphology $(P<0.001$ and 0.03$)$. $K^{\text {trans }}$ was not significantly different $(P=0.24$ and 0.99$)$.

\section{DATA CONCLUSION:}

Regions of prostate cancer lesions that are invisible on mpMRI have different histopathology features than visible regions. This may have implications for monitoring during active surveillance and focal treatment strategies.

\section{KEYWORDS:}

Gleason subpatterns; multiparametric MRI; prostate cancer; tumor delineation; volume assessment 
The current definition of clinically significant prostate cancer is based on a combination of criteria including prostate-specific antigen level, clinical stage, Gleason score, number of positive cores, and extent of prostate cancer involvement of the biopsy [1]. The latter two parameters are indirect measures of prostate tumor volume and therefore are not precise. Accurate and robust volume assessment of prostate cancer lesions is becoming more important to guide treatment decisions [2] in particular for eligibility assessment and monitoring of patients in active surveillance [2,3], as well as for guidance in focal treatment options [4].

As multiparametric magnetic resonance imaging (mpMRI) is currently being used in the diagnostic work-up of prostate cancer $[5,6]$, it would be practical if mpMRI could also be used for assessment of tumor volume [2]. Multiparametric MRI is useful to identify whether a patient has clinically significant prostate cancer: sensitivity values of $93 \%$ and $96 \%$ have been reported from two large trials based on patients with suspected prostate cancer [7, 8]. However, the sensitivity on a lesion basis is much lower: about half of the individual tumor foci appears to be not visible on mpMRI [9, 10]. Moreover, mpMRI tends to underestimate the size of large lesions [11-13]. Bratan et al identified that the accuracy of volume assessment is influenced by the size of lesions, Gleason score, and tumor Likert score [13]. For these reasons, tumor volume estimation with mpMRI should be considered with care in clinical practice [13], because this could have consequences for risk stratification [11].

To be able to improve volume assessment of lesions with mpMRI, we first need to understand why parts of lesions are not visible. Based on histopathology a single lesion can consist of a combination of Gleason patterns (GPs) and even within a single GP multiple architectural subpatterns can be present [14]. Langer et al indicated that there is a significant relation between histological features of normal and malignant prostate tissue and mpMRI parameters [15]. Moreover, different Gleason subpatterns have different signal intensities on $T_{2}$-weighted $\left(T_{2} W\right)$ images [16]. Therefore, we hypothesized that the underlying intratumor histopathology heterogeneity may impact the visibility of a lesion on mpMRI. Thus, the purpose of this study was to investigate why some parts (ie, regions) of lesions are not visible on mpMRI by comparing their histopathology features to those of visible regions.

\section{Materials and Methods}

\section{Patients}

Retrospective analysis was performed of prospectively collected data of 34 biopsy-proven prostate cancer patients (median 69 years, range 54-76 years). The patients were consecutively included (October 2014 to April 2016) in three centers after Institutional Review Boards approval and written informed consent. Exclusion criteria were contraindications for MRI, prior treatment of prostate cancer, and transurethral resection of the prostate. 
The pretreatment mpMRI exam consisted of $\mathrm{T}_{2} \mathrm{~W}$ images in three directions, fat-saturated $3 \mathrm{D} \mathrm{T}_{1^{-}}$ weighted images, diffusion-weighted imaging (DWI), $T_{2}$ mapping, and dynamic contrast-enhanced (DCE) MRI. Patients were scanned with one 1.5T system and two 3.0T systems (Philips Healthcare, Best, Netherlands). Details of the scanning parameters are presented in Table 1. An apparent diffusion coefficient (ADC) map was calculated from DWI using a semilogarithmic linear fit through the data of b-values 200 and $1000 \mathrm{~s} / \mathrm{mm}^{2}$. A $\mathrm{T}_{2}$ map was created from multiecho spin echo data by fitting a monoexponential decay function as implemented in the scanner software [17]. For quantitative analysis of the DCE data, the signal intensities were converted to concentration values using a baseline $T_{1}$ map generated from a variable flip angle series acquired (3D spoiled gradient echo sequence, repetition time [TR] $20 \mathrm{msec}$, echo time [TE] $4 \mathrm{msec}$, flip angles of 3, 6, 10, 20, and $30^{\circ}$ ) [18]. The standard Tofts model was applied to estimate $K^{\text {trans }}$ using a deconvolution implementation [19]. As input for the model we used patient-specific arterial input functions derived from the magnitude data for the 1.5T system, whereas the arterial input functions were derived from the complex data for the data from the 3T systems [20]. All quantitative maps were rigidly registered to the axial $T_{2} W$ image. When scanned with an endorectal coil, the $T_{2} W$ image with endorectal coil was deformable registered to the $\mathrm{T}_{2} \mathrm{~W}$ image without endorectal coil. Before the start of patient inclusion, calibration measurements were performed to check consistency in the quantitative MRI parameters between the three institutes.

Two urogenital radiologists with 14 (S.W.T.P.J) and 6 years (I.G.S.) experience delineated suspicious lesions with a Prostate Imaging Reporting and Data System (PI-RADS) score of 3 and higher on the registered images [5]. Data of two test patients outside this cohort were used to reach agreement about the way they delineated: lesion border was based on low signal intensity on T2W MRI, high signal intensity on the DWI image with highest b-value, and low signal intensity on the ADC map. If the delineations of the two radiologists did not overlap, this patient was discussed to reach a consensus delineation. The peripheral zone (PZ), transition zone (TZ), and posterior and anterior sectors were segmented on $\mathrm{T} 2 \mathrm{~W}$ scans according to the prostate sector map [5].

\section{Histopathology}

Patient-customized 3D-printed molds were created using the transversal $\mathrm{T}_{2} \mathrm{~W}$ images [21]. Specimens were fixated ( $10 \%$ formalin) in the mold and sliced in 3-mm slices parallel to the MRI slices. Hematoxylin and eosin-stained wholemount slices were digitized (Aperio Technologies, Vista, CA). Lesions and GP 3,4 , and 5 were manually segmented (resolution $0.5 \mu \mathrm{m} / \mathrm{pixel}$ ).

\section{Imaging-Histopathology Interpretation}

To link the delineations made by the readers on MRI to the lesions in histopathology, the histopathology slices were registered to the $T_{2} W$ images using a registration method based on anatomical landmarks visible on the $\mathrm{T}_{2} \mathrm{~W}$ and the histopathology slices [22]. The error in the registration was assessed by independent observers (Supporting information). 
The concordance between mpMRI delineations and histopathology lesions was evaluated on three levels using the histopathology as ground truth: patient-level, lesion-level, and region-level (Fig. 1). Patient-level: As all patients included in this study had known biopsy-proven prostate cancer, a patient was classified with visible cancer when both readers identified on $\mathrm{mpMRI}$ at least one suspicious lesion in the prostate with PI-RADS $\geq 3$, whereas a patient was classified with "invisible cancer" in the absence of suspicious lesions. Lesion-level (Fig. 1d): Lesions were identified on histopathology. Lesions were considered separate when the distance between the closest borders of the lesions was more than $3 \mathrm{~mm}$ [24]. A lesion, identified on histopathology, was classified as visible on $\mathrm{mpMRI}$ when both readers made a delineation in the same prostate zone, sector, and laterality as on histopathology [23]. A lesion was called invisible on mpMRI when it was missed by both readers. Region-level (Fig. 1e): Region-level analysis was carried out only for lesions that were classified as visible. Regions were identified per histopathology slice to be able to take the histopathology heterogeneity into account. If a lesion was present in multiple slices, this resulted in multiple regions per lesion. A region was classified as visible when it was delineated by both readers and invisible when it was not delineated by any. A region was classified as inconsistently delineated when delineated by only one of the readers. As for these regions it was unclear if they were visible or not, they were not further analyzed.

Both at the lesion- and at region-level we assessed several characteristics: size, location, and histopathology features. For lesions, their size was calculated with the ellipsoid volume formula [5].For regions, their size (ie, surface area) was calculated from the number of voxels inside a region. For location, the zone (PZ or TZ) and sector (anterior or posterior) were determined in which the majority of the voxels of a lesion or region were located. From the histopathology data, first the International Society of Urological Pathology (ISUP) grade 1-5 were determined from the percentage of GP within a lesion or region [25]. In addition, several subpatterns were assessed [14] (Fig. 2). The density of neoplastic glands was either identified as "dense" or "intermediate" (Fig. 2a) [16]. A GP 4 region was classified as having cribriform growth if a part consisted of expansile rounded tumor areas with a cribriform pattern, large-sized glands with glomeruloid features showing a cribriform pattern, or complex fused glands with irregular cribriform areas (Fig. 2b) [14]. In addition to the subpatterns classification suggested by Kweldam et al [14], a lesion or a region was classified as having homogeneous morphology when the morphology of all tumor cells was the same, and heterogeneous morphology when more than one type of morphology was present; for instance, if both acinar and foamy tumor cells were present (Fig. 2c). Histopathology analyses were based on consensus between a trained researcher (G.G.) and a uropathologist with more than 6 years of experience (J.d.J.).

\section{Statistical Analyses}

Sensitivity of mpMRI was calculated on a patient-, lesion-, and region-level. Univariate and multivariate generalized linear mixed-effect modeling (GLMM) was used to investigate whether size, 
location, or histopathology features explain why a lesion or region was not visible on $\mathrm{mpMRI}$ (RStudio, Boston, MA, v. 1.1.383, 2017, Ime4 package) [26]. For ISUP grade, the lesions and regions were divided into two groups: ISUP grade 1 and 2 vs. ISUP grade 3 or larger. Size was classified as smaller or larger than $0.5 \mathrm{~cm}^{3}$ for lesions, and smaller or larger than $0.5 \mathrm{~cm}^{2}$ for regions. For the lesion-level GLMM, patients and lesions were added as random effects. For the region-level GLMM, regions were also added to the random effects to take into account that multiple regions could relate to the same lesion. In a forward approach, we investigated which combination of factors resulted in the best model fit using analysis of variance (ANOVA). To understand how location and the histopathology features affect the visibility on mpMRI, the median mpMRI values ( $T_{2}$ map, $A D C$, and $\left.\mathrm{K}^{\text {trans }}\right)$ of the lesions and regions were compared for each of these characteristics using one-way ANOVA with a statistical significance level of 0.05 (SPSS, Chicago, IL, v. 22, 2013).

Due to the unavailability of (parts of) wholemount slices, delineations and the imaging data were not taken into account for which histopathology information was not available. For one patient, missing DCE-MRI data were substituted with the median values of the $\mathrm{K}^{\text {trans }}$ from all other patients.

\section{Results}

Four out of 34 patients were excluded from analysis due to insufficient quality and slice orientation of the histopathology slides $(n=3)$ and hormonal therapy between the MRI and the prostatectomy $(n=1)$ [27]. The clinical characteristics of the remaining 30 are presented in Table 2.

The sensitivity for prostate cancer detection with mpMRI at the patient level was 0.97 (Supplemental Table S1). In total, 69 lesions were identified on histopathology with a median size of $0.3 \mathrm{~cm}^{3}$ (range $0.0-16.8 \mathrm{~cm}^{3}$ ). From these lesions 13 had ISUP grade $\geq 3$, of which two were not visible. The sensitivity for detecting all lesions on mpMRI was 0.51 , whereas the sensitivity for detecting lesions with ISUP grade $\geq 3$ was 0.85 (Table S1). Anterior location, small size, and ISUP grade $1-2$ increased the chance of missing lesions on mpMRI (Table S2). Lesions smaller than $0.5 \mathrm{~cm}^{3}$ had a $\beta=4.1$ times higher chance of being missed than lesions larger than $0.5 \mathrm{~cm}^{3}$. A similar result was found for anterior lesions compared with posterior lesions $(\beta=3.8)$. ISUP grade $1-2$ lesions had a $\beta=3.0$ times higher chance of not being detected compared with ISUP grade $\geq 3$ lesions. Figure S1 shows the imaging characteristics of the lesions with different location and histopathology features.

At the region level we investigated possible explanations why some regions of a visible lesion were invisible on mpMRI. Figure 3a shows an example of a visible ISUP grade 4 lesion with almost overlapping delineations by both readers. Figure $3 \mathrm{~b}$ shows an example of a visible lesion with ISUP grade 1 , but a large region of the lesion was not delineated by the readers. In total, the characteristics of 83 visible regions (surface area range $0.01-4.4 \mathrm{~cm}^{2}$ ) and 36 invisible regions (surface area range $0.06-2.7 \mathrm{~cm}^{2}$ ) were analyzed (Table 3). A median of $14 \%$ (range $6-41 \%$ ) of the volume of a lesion was inconsistently delineated by the two readers and not taken into account in 
further analyses. The sensitivity of visible regions in TZ was lower than regions in PZ (0.56 vs. 0.76). The sensitivity of visible regions with ISUP grade 1-2 was not different from the sensitivity of delineating ISUP grade $\geq 3$ regions, as the confidence intervals overlapped. The sensitivity for regions with intermediate density was lower compared with dense regions ( 0.35 vs. 0.78 ). The same was true for regions with heterogeneous morphology compared with regions with homogeneous morphology (sensitivity $=0.44$ vs. 0.72 ).

Multivariate analysis showed that the regions with intermediate density, heterogeneous tumor morphology, and location in TZ were more likely to be invisible on mpMRI (Table 4). The intermediate density regions had a $\beta=3.2$ times higher chance of being invisible compared with dense regions. Low ISUP grade, small size, anterior location, and presence of cribriform growth did not have a significant influence on missing a region. This is in contradiction to the results on the lesion level, where ISUP grade was an explaining factor for missing an entire lesion. However, we did not observe a relation between ISUP grade and intermediate density and heterogeneous morphology: in ISUP grade 1-2 regions $20 \%$ had an intermediate density, while in ISUP grade $\geq 3$ regions $16 \%$ had an intermediate density. Similarly, in ISUP grade 1-2 regions $9 \%$ had heterogeneous morphology, which was comparable for ISUP grade $\geq 3$ regions with $6 \%$ heterogeneous morphology. This illustrates that the intermediate density and heterogeneous morphology were independent from ISUP grade. In addition, in four patients for whom regions with ISUP grade $\geq 3$ were invisible, these regions had either intermediate density or heterogeneous morphology, whereas the visible regions for those patients were dense and had homogeneous morphology.

To understand how the different tested factors affect mpMRI data, their imaging characteristics were analyzed (Fig. 4). No significant differences in $T_{2}, A D C$, and $K^{\text {trans }}$ were observed for regions in different zones and sectors $(P=0.14,0.33,0.57$, and $P=0.23,0.72,0.17)$. In regions with ISUP grade $\geq 3$, the $A D C$ values were significantly lower and $K^{\text {trans }}$ was significantly higher than in regions with ISUP grade $1-2(P=0.02$ and 0.007$)$. No significant difference was found for the $T_{2}$ values $(P=$ $0.19)$. In regions with intermediate density $T_{2}$ and $A D C$ values were significantly higher than in dense regions $(P=0.002$ and $<0.001)$, while $K^{\text {trans }}$ was not different $(P=0.24)$. In addition, in regions with heterogeneous morphology $T_{2}$ and $A D C$ values were significantly higher than for regions with homogeneous morphology $(P<0.001$ and 0.03$)$, while $K^{\text {trans }}$ was not different $(P=0.99)$. ADC values in regions where cribriform growth was present were significantly lower than the regions without cribriform growth $(P=0.03)$, while $\mathrm{T}_{2}$ and $\mathrm{K}^{\text {trans }}$ were not different $(P=0.33$ and 0.07$)$.

Figure 5 shows the histopathology features and imaging characteristics of delineated and missed regions of the lesions for four patients. In all cases, the delineated areas on mpMRI were dense on histopathology, had homogeneous morphology, and were located in the PZ. The signal intensities of $\mathrm{T}_{2} \mathrm{~W}$ and $\mathrm{ADC}$ values were low in these regions. In the first two cases (Fig. $5 \mathrm{a} \& \mathrm{~b}$ ), large regions of ISUP grade $\geq 3$ were missed by both readers on $T_{2} W$ and $A D C$. These regions had an intermediate 
density and homogeneous morphology and were located either in PZ or TZ. In the third example (Fig. 5c), the area that was missed was dense, but with heterogeneous morphology. The fourth example (Fig. $5 \mathrm{~d}$ ) shows a large missed region that had both intermediate density and heterogeneous morphology.

\section{Discussion}

Accurate tumor volume assessment is necessary for treatment decision and monitoring strategies in prostate cancer. Tumor volume may be underestimated on mpMRI [11]. In this proof-of-principle study, we linked the delineations by readers on mpMRI to detailed histopathology characteristics to identify reasons for this underestimation. Although the characteristics of invisible lesions and invisible regions were not compared directly, from our results we observed that the factors for missing an entire lesion were different from missing a part of it: while size and ISUP grade were important for lesion detection, other histopathological features explain why a part (ie, a region) of this lesion was invisible. Specifically, a region of a lesion was more likely to be missed on mpMRI when it had intermediate density, heterogeneous tumor morphology, and was located in TZ.

The per-lesion sensitivity of our data was in the same range as reported by other studies [10]. The detailed histopathology analysis led to segmentation of many small low-grade lesions that were all invisible on mpMRI. This may explain why this study showed lower sensitivity for lesion detection than Borofsky et al [11]. Like other studies, size, ISUP grade, and location were important factors for missing entire lesions [10, 28-31]. Rosenkrantz et al found that visible and invisible lesions have a different density [31]. In our study, this was only true in univariate analysis.

Of the visible lesions, some regions were not visible, which will result in underestimation of tumor volume. The invisible regions have different histopathology characteristics than visible regions, confirming previous results that a prostate lesion consists of a combination of multiple subpatterns that represent themselves differently on mpMRI $[14,16]$. Bratan et al also looked at density as an influencing factor for the accuracy of volume assessment: from their analysis the Gleason score, size, and Likert score were significant predictors for accurate volume assessment [13]. The discrepancy could be explained by the study design, as their study was performed on a lesion level, while our study was performed on a region level.

The imaging values of visible and invisible regions did not differ between different prostate locations (ie, PZ vs. TZ and anterior vs. posterior). This suggests that the conspicuity of lesions in different locations of the prostate is affected by differences in tissue surrounding the prostate cancer lesion rather than differences in tumor characteristics. This hypothesis arises from studies reporting on the normal zone imaging characteristics showing that the $T_{2}$ and $A D C$ values of lesions are more similar to those in normal TZ than in the normal PZ $[32,33]$. Our data confirmed previous studies showing that $A D C$ and $K^{\text {trans }}$ values were significantly different in regions with low- and high-grade cancer [34, 
35]. In addition, we showed that regions with intermediate density had higher $\mathrm{T}_{2}$ and $A D C$ values than the dense regions, consistent with other studies [16, 36]. Regions with heterogeneous morphology also had higher $\mathrm{T}_{2}$ and $A D C$ values than the homogeneous regions. As the readers based their delineations on the $T_{2} W$ images and DWI, this could explain why regions with intermediate density and heterogeneous morphology were missed. Interestingly, $\mathrm{K}^{\text {trans }}$ was not different for any of these features. Although the role of DCE-MRI is limited for lesion detection in the PI-RADS v2 guidelines, for tumor volume assessment this role should be further evaluated. This is in line with the findings of Bratan et al indicating that the combined volume delineated on individual $T_{2} W, A D C$, and DCE images resulted in a better volume estimation [13].

Most lesions with cribriform growth were detected in our study, consistent with Prendevill et al [37]. This is promising, as cribriform growth is a prognostic factor for disease-specific mortality [38]. These lesions with cribriform growth were mainly mixed with poorly formed/fused morphology, which have a better mpMRI conspicuity than lesions with pure cribriform morphology [39]. In contrast, there were many regions with intermediate density in our study population and those were often missed. Therefore, we expect that this will also often occur in clinical practice and will result in underestimation of tumor volume. In this study we investigated all histopathology lesions. However, not all of them will have the same importance for the diagnosis and prognosis of a patient. In addition, the clinical relevance of invisible regions with intermediate density and heterogeneous morphology remains unclear and warrants further investigation by studying their genetic background. With a growing population choosing active surveillance, we need to be aware of this error, especially when mpMRI is propagated as a monitoring tool without any biopsy procedure [40]. Focal treatment plans may be expanded by margins beyond the visible lesion on mpMRI [11] at the cost of increasing the treated healthy volume. Therefore, we recommend developing guidelines for more accurate lesion delineation.

Although we analyzed a considerable number of lesions and regions and applied GLMM to account for the interdependence at the patient-, lesion-, and region-level, still the small number of patients may have led to some factors being not significant and may not represent the true variability of the disease. Because of the size of our study, we limited the histopathology analysis to a few subpatterns. Our cohort consisted of prostatectomy patients, as this is necessary for histopathologyimaging interpretations, but this limits the generalizability of the results. Another limitation is the way tumors were delineated on mpMRI. As there is currently no consensus about prostate cancer delineation, differences with other studies [13] may exist. Furthermore, image quality, and therefore tumor detection and delineation, could have been affected by image registration. Another factor that could have influenced tumor conspicuity is the use of a 1.5T system at one of the institutes. However, we investigated the effect of different MR systems by adding institute as a random effect to the mixed modeling and observed that this did not improve the model performance. Data analysis was limited to the availability of histopathology slices. 
In conclusion, regions of prostate cancer lesions that are not visible on mpMRI have different histopathology features than regions that are visible. Regions with intermediate density and heterogeneous tumor morphology are likely to be missed on prostate mpMRI. This could explain tumor volume underestimation of prostate cancer lesions with $\mathrm{mpMRI}$ and may have implications for monitoring during active surveillance and focal treatment strategies in prostate cancer management.

\section{Acknowledgments}

We thank Iris Walraven, PhD, for the consult on statistical analyses. We thank Prof. Theodorus van der Kwast from Toronto General Hospital for advising on improvement of the article. This study was part of the DR THERAPAT project (FP7-ICT-2011-9, Project No. 600852). 


\section{References}

[1] Watson MJ, George AK, Maruf M, et al. Risk stratification of prostate cancer: Integrating multiparametric MRI, nomograms and biomarkers. Future Oncol 2016; 12: 2417- 2430.

[2] Schoots IG, van der Kwast TH. MR imaging in prostate tumor volume assessment: How accurate? In: L Klotz (ed.). Active surveillance for localized prostate cancer. Current Clinical Uruology. Cham, Switzerland: Humana Press; 2018. p 95- 109.

[3] Wolters T, Roobol MJ, van Leeuwen PJ, et al. A critical analysis of the tumor volume threshold for clinically insignificant prostate cancer using a data set of a randomized screening trial. $J$ Urol 2011; 185: 121- 125.

[4] van der Poel HG, van den Bergh RCN, Briers E, et al. Focal therapy in primary localised prostate cancer: The European Association of Urology position in 2018. Eur Urol 2018; 74: 84- 91.

[5] Purysko AS, Rosenkrantz AB, Barentsz JO, Weinreb J, Macura K. PI-RADS Version 2: A pictorial update. Radiographics 2016; 36: 1354- 1372.

[6] Kasivisvanathan V, Rannikko AS, Borghi M, et al. MRI-targeted or standard biopsy for prostate-cancer diagnosis. N Engl J Med 2018; 378: 1767- 1777.

[7] Ahmed HU, Arya M, Freeman A, Emberton M. Do low-grade and low-volume prostate cancers bear the hallmarks of malignancy? Lancet Oncol 2012; 13: e509-e517.

[8] Thompson JE, van Leeuwen PJ, Moses D, et al. The diagnostic performance of multiparametric magnetic resonance imaging to detect significant prostate cancer. $J$ Urol 2016; 195: 1428- 1435.

[9] Lee MS, Moon MH, Kim YA, et al. Is prostate imaging reporting and data system version 2 sufficiently discovering clinically significant prostate cancer? Per-lesion radiology-pathology correlation study. Am J Roentgenol 2018; 211: 114- 120.

[10] Johnson DC, Raman SS, Mirak SA, et al. Detection of individual prostate cancer foci via multiparametric magnetic resonance imaging. Eur Urol 2018; 75: 712- 720.

[11] Borofsky S, George AK, Gaur S, et al. What are we missing? False-negative cancers at multiparametric MR imaging of the prostate. Radiology 2018; 286: 186- 195.

[12] Priester A, Natarajan S, Khoshnoodi P, et al. Magnetic resonance imaging underestimation of prostate cancer geometry: Use of patient specific molds to correlate images with whole mount pathology. J Urol 2017; 197: 320-326.

[13] Bratan F, Melodelima C, Souchon R, et al. How accurate is multiparametric MR imaging in evaluation of prostate cancer volume? Radiology 2015; 275: 144- 154.

[1] Kweldam CF, van Leenders GJ, van der Kwast T. Grading of prostate cancer: A work in progress. Histopathology 2019; 74: 146- 160.

[15] Langer DL, Evans AJ, Plotkin A, Trachtenberg J, Wilson BC, Haider MA. Prostate tissue composition and MR measurements: Investigating the relationships between ADC, T2, Ktrans, ve, and corresponding histologic features. Radiology 2010; 255: 485- 494. 
[16] Downes MR, Gibson E, Sykes J, Haider M, van der Kwast TH, Ward A. Determination of the association between T2-weighted MRI and Gleason sub-pattern: A proof of principle study. Acad Radiol 2016; 23: 1412- 1421.

[17] Bos C, Duijndam A, Sénégas J. Reference phantom validation of T2-mapping: Maximum likelihood estimation of T2 from magnitude phased-array multi-echo data. In: Proc 17th Annual Meeting ISMRM, Honolulu; 2009. p 4526.

[18] Schabel MC, Parker DL. Uncertainty and bias in contrast concentration measurements using spoiled gradient echo pulse sequences. Phys Med Biol 2008; 53: 2345- 2373.

[19] Murase K. Efficient method for calculating kinetic parameters using T1-weighted dynamic contrast-enhanced magnetic resonance imaging. Magn Reson Med 2004; 51: 858- 862.

[20] Klawer EME, van Houdt PJ, Simonis FFJ, et al. Improved repeatability of dynamic contrastenhanced MRI using the complex MRI signal to derive arterial input functions: A test-retest study in prostate cancer patients. Magn Reson Med 2019; 81: 3358- 3369.

[21] Bourne RM, Bailey C, Johnston EW, et al. Apparatus for histological validation of in vivo and ex vivo magnetic resonance imaging of the human prostate. Front Oncol 2017; 7: 47.

[22] Dinh CV, Steenbergen P, Ghobadi G, et al. Multicenter validation of prostate tumor localization using multiparametric MRI and prior knowledge. Med Phys 2017; 44: 949-961.

[23] Truong M, Hollenberg G, Weinberg E, Messing EM, Miyamoto H, Frye TP. Impact of Gleason subtype on prostate cancer detection using multiparametric magnetic resonance imaging: Correlation with final histopathology. J Urol 2017; 198: 316- 321.

[24] Huang CC, Deng F-M, Kong MX, Ren Q, Melamed J, Zhou M. Re-evaluating the concept of "dominant/index tumor nodule" in multifocal prostate cancer. Virchows Arch 2014; 464: 589- 594.

[25] Epstein JI, Egevad L, Amin MB, Delahunt B, Srigley JR, Humphrey PA. The 2014 International Society of Urological Pathology (ISUP) consensus conference on Gleason grading of prostatic carcinoma definition of grading patterns and proposal for a new grading system. Am J Surg Pathol 2016; 40: 244- 252.

[26] Bates D, Maechler M, Bolker B, Walker S. Fitting linear mixed-effects models using Ime4. J Stat Softw 2015; 67: 1- 48.

[27] Van der Roest RC, van Houdt PJ, Heijmink SW, et al. The effects of enzalutamide monotherapy on multiparametric 3T MR imaging in prostate cancer. Urol Case Reports 2016; 7: 67-69.

[28] Le JD, Tan N, Shkolyar E, et al. Multifocality and prostate cancer detection by multiparametric magnetic resonance imaging: Correlation with whole-mount histopathology. Eur Urol 2015; 67: $569-576$.

[29] De Visschere PJL, Naesens L, Libbrecht L, et al. What kind of prostate cancers do we miss on multiparametric magnetic resonance imaging? Eur Radiol 2016; 26: 1098- 1107.

[30] Lewis S, Besa C, Rosen A, et al. Multiparametric magnetic resonance imaging for transition zone prostate cancer: Essential findings, limitations, and future directions. Abdom Radiol 2017; 42: 2732- 2744. 
[31] Rosenkrantz AB, Mendrinos S, Babb JS, Taneja SS. Prostate cancer foci detected on multiparametric magnetic resonance imaging are histologically distinct from those not detected. J Urol 2012; 187: 2032- 2038.

[32] Foltz WD, Wu A, Chung P, Catton C, et al. Changes in apparent diffusion coefficient and T2 relaxation during radiotherapy for prostate cancer. J Magn Reson Imaging 2013; 37: 909916.

[33] Dinis Fernandes C, van Houdt PJ, Heijmink SWTPJ, et al. Quantitative 3T multiparametric MRI of benign and malignant prostatic tissue in patients with and without local recurrent prostate cancer after external-beam radiation therapy. J Magn Reson Imaging 2019; 50: 269- 278

[34] Hambrock T, Somford DM. Relationship between apparent diffusion coefficients at 3.0-T MR imaging and Gleason grade in peripheral zone prostate cancer. Radiology 2011; 259: 453461.

[35] Vos EK, Litjens GJS, Kobus T, et al. Assessment of prostate cancer aggressiveness using dynamic contrast-enhanced magnetic resonance imaging at 3 T. Eur Urol 2013; 64: 448- 455.

[36] Langer DL, van der Kwast TH, Evans AJ, et al. Intermixed normal tissue within prostate cancer: Effect on MR imaging measurements of apparent diffusion coefficient and T2-sparse versus dense cancers. Radiology 2008; 249: 900-908.

[37] Prendeville $S$, Gertner M, Maganti $M$, et al. Role of magnetic resonance imaging targeted biopsy in detection of prostate cancer harboring adverse pathological features of intraductal carcinoma and invasive cribriform carcinoma. J Urol 2018; 200: 104- 113.

[38] Kweldam CF, Kümmerlin IP, Nieboer D, et al. Disease-specific survival of patients with invasive cribriform and intraductal prostate cancer at diagnostic biopsy. Mod Pathol 2016; 29: 630-636.

[39] Truong M, Feng C, Hollenberg G, et al. A comprehensive analysis of cribriform morphology on magnetic resonance imaging/ultrasound fusion biopsy correlated with radical prostatectomy specimens. J Urol 2018; 199: 106- 113.

[40] Moore CM, Giganti F, Albertsen P, et al. Reporting magnetic resonance imaging in men on active surveillance for prostate cancer: The PRECISE recommendations-A report of a European School of Oncology Task Force. Eur Urol 2017; 71: 648- 655.

[41] van Houdt PJ, Agarwal HK, van Buuren LD, et al. Performance of a fast and high-resolution multi-echo spin-echo sequence for prostate $\mathrm{T} 2$ mapping across multiple systems. Magn Reson Med 2018; 79: 1586- 1594. 
Table 1: Details of Scanning Parameters

\begin{tabular}{|c|c|c|c|c|}
\hline & Parameter & System $A^{a}$ & System $\mathbf{B}^{\mathbf{b}}$ & System Cc \\
\hline No. of patients & & $n=12$ & $n=7$ & $n=3$ \\
\hline \multirow[t]{7}{*}{$\begin{array}{c}\text { Turbo spin echo } \\
\text { T2-weighted }\end{array}$} & $\mathrm{FOV}\left(\mathrm{mm}^{3}\right)$ & $280 \times 350 \times 120$ & $240 \times 240 \times 176$ & 140x140x75 (with endo) \\
\hline & & & & $\begin{array}{l}\text { 200x282x75 (without } \\
\text { endo) }{ }^{\mathrm{d}}[140 \times 140 \times 75]\end{array}$ \\
\hline & $\begin{array}{l}\text { Acquired voxel size } \\
\left(\mathrm{mm}^{3}\right)\end{array}$ & $1.1 \times 1.1 \times 3$ & $0.8 \times 0.8 \times 3$ & $0.46 \times 0.58 \times 3$ (with endo) \\
\hline & & & & $\begin{array}{l}0.7 \times 0.7 \times 3 \text { (without } \\
\text { endo) }{ }^{\mathrm{d}}[0.7 \times 0.7 \times 3]\end{array}$ \\
\hline & $\begin{array}{l}\text { Reconstructed } \\
\text { voxel size }\left(\mathrm{mm}^{3}\right)\end{array}$ & $0.6 \times 0.6 \times 3$ & $0.4 \times 0.4 \times 3$ & $0.27 \times 0.27 \times 3$ (with endo) \\
\hline & & & & $\begin{array}{l}0.4 \times 0.4 \times 3 \text { (without } \\
\text { endo) }{ }^{\mathrm{d}}[0.4 \times 0.4 \times 3]\end{array}$ \\
\hline & TR/TE (msec) & $\begin{array}{l}\text { Range } 2500- \\
5000 / 80\end{array}$ & $\begin{array}{l}\text { Range 2500- } \\
5000 / 95\end{array}$ & Range $2500-5000 / 120$ \\
\hline \multirow{6}{*}{$\begin{array}{c}\text { Single-shot EPI } \\
\text { DWI }\end{array}$} & $\mathrm{FOV}\left(\mathrm{mm}^{3}\right)$ & $262 \times 415 \times 120$ & $262 \times 262 \times 66$ & $160 \times 180 \times 63$ [256x256x66] \\
\hline & $\begin{array}{c}\text { Reconstructed } \\
\text { voxel size }\left(\mathrm{mm}^{3}\right)\end{array}$ & $1.3 \times 1.3 \times 5$ & $1.4 \times 1.4 \times 3$ & $1.1 \times 1.1 \times 3[1.3 \times 1.3 \times 3]$ \\
\hline & TR/TE (msec) & $3500 / 67$ & $3500 / 65$ & $3500 / 59[3600 / 57]$ \\
\hline & b-values $\left(\mathrm{s} / \mathrm{mm}^{2}\right)$ & $0(1), 200(4), 600$ & 0 (5), 200 (5), 500 & $\begin{array}{c}0(1), 200(4), 600(4) \\
1000\end{array}$ \\
\hline & (averages) & $(4), 1000(8)$ & $(5), 1000(5)$ & $(8)$ \\
\hline & $\begin{array}{c}\text { Parallel imaging } \\
\text { factor }\end{array}$ & 3 & 3 & 2 \\
\hline \multirow[t]{6}{*}{$\begin{array}{c}\text { Multi-echo spin } \\
\text { echo T2 mapping }\end{array}$} & FOV $\left(\mathrm{mm}^{3}\right)$ & $262 \times 262 \times 60$ & $262 \times 262 \times 60$ & $170 \times 170 \times 60$ \\
\hline & $\begin{array}{c}\text { Acquired voxel size } \\
\left(\mathrm{mm}^{3}\right)\end{array}$ & $2.3 \times 2.3 \times 3$ & $1.5 \times 1.5 \times 3$ & $0.8 \times 0.8 \times 3[1 \times 1 \times 3]$ \\
\hline & $\begin{array}{c}\text { Reconstructed } \\
\text { voxel size }\left(\mathrm{mm}^{3}\right)\end{array}$ & $1.4 \times 1.4 \times 3$ & $0.8 \times 0.8 \times 3$ & $0.4 \times 0.4 \times 3[0.6 \times 0.6 \times 3]$ \\
\hline & $\mathrm{TR} / \mathrm{TE} / \Delta \mathrm{TE}(\mathrm{msec})$ & $\begin{array}{c}\text { Range 2000- } \\
5000 / 30 / 15 \\
\end{array}$ & $\begin{array}{c}\text { Range 2000- } \\
5000 / 30 / 15\end{array}$ & $2459 / 32 / 16$ \\
\hline & No. echoes & 10 & 10 & 12 \\
\hline & $\begin{array}{c}\text { Parallel imaging } \\
\text { factor }\end{array}$ & 2 & 3 & $2^{\mathrm{e}}$ \\
\hline \multirow{10}{*}{$\begin{array}{c}\text { 3D spoiled gradient } \\
\text { echo DCE }\end{array}$} & $\mathrm{FOV}\left(\mathrm{mm}^{3}\right)$ & $262 \times 262 \times 60$ & $262 \times 262 \times 60$ & $360 \times 520 \times 60$ \\
\hline & $\begin{array}{c}\text { Acquired voxel size } \\
\left(\mathrm{mm}^{3}\right)\end{array}$ & $2.5 \times 2.5 \times 6$ & $2 \times 2 \times 3$ & $1.8 \times 1.8 \times 6[2.3 \times 2.3 \times 6]$ \\
\hline & $\begin{array}{c}\text { Reconstructed } \\
\text { voxel size }\left(\mathrm{mm}^{3}\right) \\
\end{array}$ & $1.4 \times 1.4 \times 3$ & $1.2 \times 1.2 \times 3$ & $1.2 \times 1.2 \times 3[1.3 \times 1.3 \times 3]$ \\
\hline & TR/TE (msec) & $5 / 1.9$ & $4 / 1.9$ & $4 / 1.9[5 / 1.9]$ \\
\hline & $\begin{array}{l}\text { Flip angle } \\
\text { (degrees) }\end{array}$ & 30 & 13 & 20 \\
\hline & $\begin{array}{c}\text { Parallel imaging } \\
\text { factor }\end{array}$ & 3 & 4 & 4 \\
\hline & $\begin{array}{c}\text { Dynamic scan time } \\
(\mathrm{sec})\end{array}$ & 2.4 & 2.5 & 2.7 [2.9] \\
\hline & No. of dynamics & 120 & 120 & 110 \\
\hline & Contrast agent & $\begin{array}{c}15 \mathrm{~mL} \text { of } 0.5 \mathrm{mM} \\
\text { Dotarem }\end{array}$ & $\begin{array}{c}15 \mathrm{~mL} \text { of } 0.5 \mathrm{mM} \\
\text { Dotarem }\end{array}$ & $15 \mathrm{~mL}$ of $0.5 \mathrm{mM}$ Dotarem \\
\hline & $\begin{array}{l}\text { Injection rate } \\
(\mathrm{mL} / \mathrm{s})\end{array}$ & 3 & 2 & 3 \\
\hline
\end{tabular}


3T Ingenia system using a 16-channel anterior and 12-channel posterior coil.

c 3T Achieva system using a 6-channel cardiac coil in combination with an endorectal coil. Three patients were scanned on an upgraded system (Achieva dStream) where we used a 16channel anterior and 12-channel posterior coil. The parameters that were different at the upgraded system, are given between square brackets.

d For those patients scanned with an endorectal coil an additional T2W scan was acquired without endorectal coil to facilitate registration with histopathology.

e In addition to standard parallel imaging a k-t undersampling scheme was applied for further acceleration of the sequence (Van Houdt et al, Magn Reson Med. 2018;79). 
Table 2: Patient Characteristics $(n=30)$

\begin{tabular}{|l|l|l|}
\hline \multicolumn{1}{|c|}{ Patient characteristic } & & \multicolumn{1}{c|}{ Median (range) } \\
\hline Age & & 69 years (54-76) \\
\hline Prostate-specific antigen & & $7.8 \mathrm{ng} / \mathrm{mL}(3.7-40.0)$ \\
\hline Time between MRI and prostatectomy & & 18.5 days (5-65) \\
\hline & & No. of patients \\
\hline T stage & cT1 & 9 \\
\hline & cT2 & 13 \\
\hline & cT3 & 6 \\
\hline unknown & 2 & \\
\hline Gleason score & & \\
\hline Pre-operative biopsy & $3+3$ & 11 \\
\hline & $3+4$ & 13 \\
\hline & $3+5$ & 2 \\
\hline & $4+3$ & 2 \\
\hline & $4+4$ & 1 \\
\hline & $4+5$ & 1 \\
\hline Prostatectomy specimen & $3+3$ & 7 \\
\hline & $3+4$ & 12 \\
\hline & $3+5$ & 4 \\
\hline & $4+3$ & 5 \\
\hline & $4+5$ & 2 \\
\hline
\end{tabular}

* This was retrieved from patients' pathology report at each center.

Table 3: Sensitivity at the Region Level

\begin{tabular}{|c|c|c|c|c|c|c|}
\hline Characteristic & Subtype & & Visible & Invisible & Sensitivity & $\begin{array}{c}95 \% \text { confidence } \\
\text { interval }\end{array}$ \\
\hline \multirow[t]{4}{*}{ Location } & Zone & $\mathrm{PZ}$ & 61 & 19 & 0.76 & $0.65-0.85$ \\
\hline & & $\mathrm{TZ}$ & 22 & 17 & 0.56 & $0.40-0.72$ \\
\hline & Sector & Posterior & 66 & 24 & 0.73 & $0.63-0.82$ \\
\hline & & Anterior & 17 & 12 & 0.59 & $0.39-0.76$ \\
\hline \multirow[t]{5}{*}{ Size } & $\begin{array}{l}\text { Surface area } \\
\left(\mathrm{cm}^{2}\right)\end{array}$ & $\geq 0.5$ & 45 & 21 & 0.68 & $0.55-0.79$ \\
\hline & & $<0.5$ & 38 & 15 & 0.72 & $0.57-0.83$ \\
\hline & & $\geq 3$ & 31 & 7 & 0.82 & $0.65-0.92$ \\
\hline & & 2 & 4 & 1 & 0.80 & $0.30-0.99$ \\
\hline & & 1 & 48 & 28 & 0.63 & $0.51-0.74$ \\
\hline \multirow[t]{6}{*}{ Sub-patterns } & Density & Dense & 75 & 21 & 0.78 & $0.68-0.86$ \\
\hline & & Intermediate & 8 & 15 & 0.35 & $0.17-0.57$ \\
\hline & $\begin{array}{l}\text { Tumor } \\
\text { morphology }\end{array}$ & Heterogeneous & 4 & 5 & 0.44 & $0.15-0.77$ \\
\hline & & Homogeneous & 79 & 31 & 0.72 & $0.62-0.80$ \\
\hline & $\begin{array}{l}\text { Cribriform } \\
\text { growth }\end{array}$ & Yes & 24 & 4 & 0.86 & $0.66-0.95$ \\
\hline & & No & 59 & 32 & 0.65 & $0.54-0.74$ \\
\hline
\end{tabular}

ISUP grade = International Society of Urological Pathology; PZ = peripheral zone; TZ = transition zone. 
Table 4: Results From the Best-Performing Generalized Linear Mixed-Effect (GLMM) Model to Indicate Which Factors Most Likely Explain Why a Region Is Invisible on mpMRI

\begin{tabular}{|l|l|l|l|}
\hline \multicolumn{1}{|c|}{ Fixed effects } & \multicolumn{1}{|c|}{$\boldsymbol{\beta}$} & \multicolumn{1}{c|}{ Std. error } & \multicolumn{1}{c|}{ P-value } \\
\hline Intermediate density & 3.2 & 0.9 & $<0.001$ \\
\hline (ref = dense) & & & \\
\hline Heterogeneous morphology & 1.9 & 0.9 & $<0.05$ \\
\hline (ref = homogeneous morphology) & & & \\
\hline TZ $($ ref = PZ) & 1.7 & 0.8 & $<0.05$ \\
\hline Intercept $\left(\beta_{0}\right)$ & -4.9 & 3.7 & 0.18 \\
\hline Residuals $\left(\varepsilon_{0}\right)$ & Median & $1^{\text {st }}$ quartile & $3^{\text {rd }}$ quartile \\
\hline & -0.23 & -0.42 & 0.40 \\
\hline
\end{tabular}

$\beta=$ regression coefficients; $T Z$ = transition zone; $P Z$ = peripheral zone; ref = reference in GLMM.

Supplementary Table 1 : Sensitivity at patient-and at lesion-level

\begin{tabular}{|c|c|c|c|c|c|c|c|}
\hline Level & Subtype & & & Visible & Invisible & Sensitivity & $\begin{array}{l}95 \% \\
\text { Confidence } \\
\text { Interval }\end{array}$ \\
\hline \multirow[t]{3}{*}{ Patient-level } & All Patients & & & 29 & 1 & 0.97 & $0.86-1.00$ \\
\hline & ISUP grade & & $\geq 3$ & 6 & 0 & 1.00 & $0.52-1.00$ \\
\hline & & & $1-2$ & 23 & 1 & 0.96 & $0.77-0.99$ \\
\hline \multirow[t]{16}{*}{ Lesion-level } & All lesions & & & 35 & 34 & 0.51 & $0.38-0.63$ \\
\hline & Location & Zone & PZ & 28 & 27 & 0.51 & $0.37-0.64$ \\
\hline & & & $\mathrm{TZ}$ & 7 & 7 & 0.50 & $0.24-0.76$ \\
\hline & & Sector & Posterior & 28 & 13 & 0.68 & $0.52-0.81$ \\
\hline & & & Anterior & 7 & 21 & 0.25 & $0.11-0.45$ \\
\hline & Size & Volume $\left(\mathrm{cm}^{3}\right)$ & $\geq 0.5$ & 20 & 5 & 0.80 & $0.59-0.92$ \\
\hline & & & $<0.5$ & 15 & 29 & 0.34 & $0.21-0.50$ \\
\hline & ISUP grade & & $\geq 3$ & 11 & 2 & 0.85 & $0.54-0.97$ \\
\hline & & & 2 & 4 & 1 & 0.80 & $0.30-0.99$ \\
\hline & & & 1 & 20 & 31 & 0.4 & $0.26-0.54$ \\
\hline & Structure/texture & Density & Dense & 27 & 18 & 0.60 & $0.44-0.74$ \\
\hline & & & Intermediate & 8 & 16 & 0.33 & $0.16-0.55$ \\
\hline & & Tumor & Heterogeneous & 5 & 2 & 0.71 & $0.30-0.95$ \\
\hline & & morphology & Homogeneous & 30 & 32 & 0.48 & $0.36-0.61$ \\
\hline & & Cribriform & Yes & 9 & 1 & 0.90 & $0.54-0.99$ \\
\hline & & growth & No & 26 & 33 & 0.44 & $0.31-0.57$ \\
\hline
\end{tabular}

Abbreviations: ISUP = International Society of Urological Pathology; PZ = peripheral zone; TZ = transition zone

Supplementary Table 2: Multivariate analysis for the best performing generalized linear mixed-effect model for missing a lesion.

\begin{tabular}{llll}
\hline Fixed effects & $\boldsymbol{\beta}$ & Std. error & $\boldsymbol{p}$-value \\
\hline $\begin{array}{l}\text { Size }<\mathbf{0 . 5} \mathbf{~ c m}^{\mathbf{3}} \\
\left(\text { ref size } \geq 0.5 \mathrm{~cm}^{3}\right)\end{array}$ & 4.1 & 1.7 & 0.016 \\
$\begin{array}{l}\text { Anterior sector } \\
\text { (ref posterior sector) }\end{array}$ & 3.8 & 1.2 & 0.002 \\
$\begin{array}{l}\text { ISUP grade 1-2 } \\
\text { (ref ISUP Grade } \geq 3 \text { ) } \\
\text { Intercept }(\boldsymbol{\beta} 0)\end{array}$ & 3.0 & 1.5 & 0.055 \\
\hline Residuals $\left(\varepsilon_{0}\right)$ & 0.2 & 0.8 & 0.73 \\
\hline & Median & $\mathbf{1}^{\text {st }}$ quartile & $\mathbf{3}^{\text {rd }}$ quartile \\
\hline & -0.01 & -0.30 & 0.32 \\
\hline
\end{tabular}

$\beta$, regression coefficients 
a T2-weighted with delineations

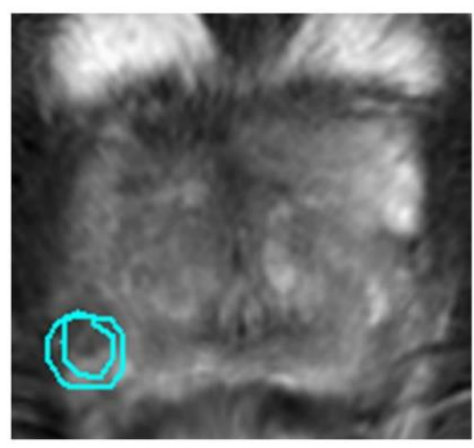

C Registered H\&E slice

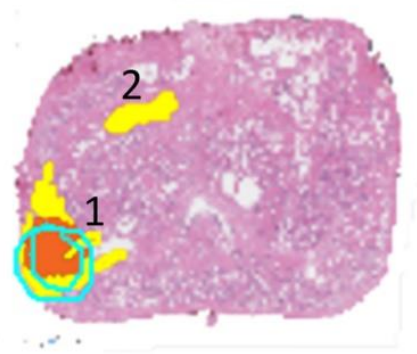

b H\&E slice with GP segmentations

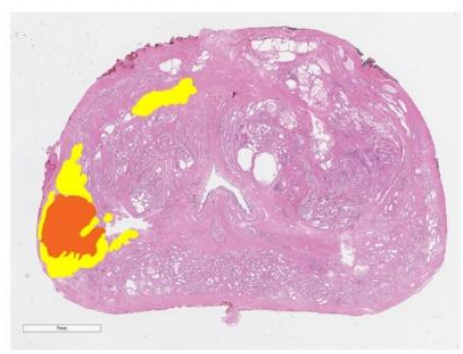

\begin{tabular}{|l|}
\hline Readers' delineations \\
\hline GP 3 \\
GP 4 \\
Visible \\
\hline Invisible \\
\hline Inconsistently delineated
\end{tabular}

d Lesion-level analysis

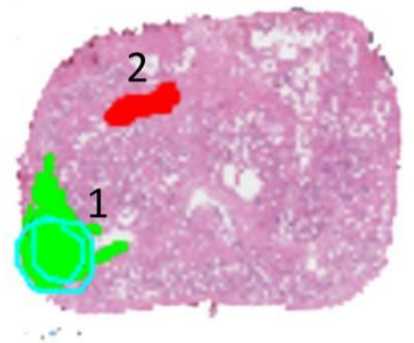

e Region-level analysis

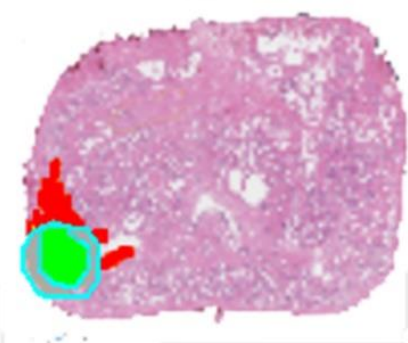

An example illustrating the lesion- and region-level analysis. (a) Both readers delineated a suspected lesion in this patient. The delineations are on the right side of the prostate, in the $\mathrm{PZ}$, and posterior sector. (b) Histopathology slice with manual GP segmentations. There are two lesions on the histopathology slice: lesion 1, ISUP grade 3, located posteriorly in the PZ, and lesion 2, ISUP grade 1, anteriorly in TZ. (c) Registered histopathology to T2W image. Lesion 1 coincides with the delineations of both readers, unlike lesion 2 that was not delineated by any of them. (d) Lesion-level analysis: lesion 1 was classified as a visible lesion, whereas lesion 2 was classified as an invisible lesion. (e) For region-level analysis, lesion 1 was subsequently divided in different regions: visible for the area that was delineated by both readers, invisible for the parts that were missed by both readers, and undefined when the area was only delineated by one of the readers. 
Figure 2
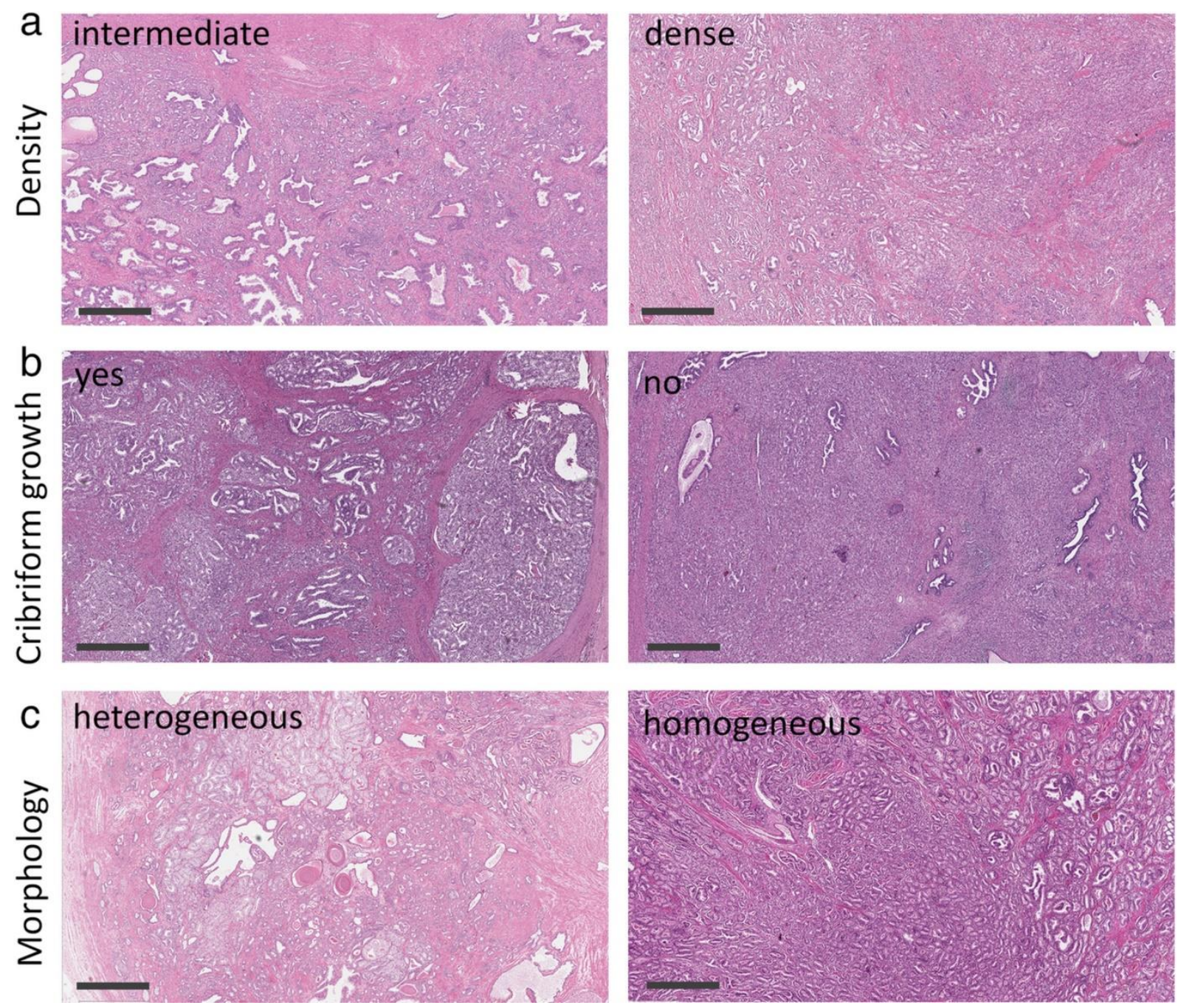

Three histopathology subpatterns to describe the density, architecture, and morphology of a lesion or region: (a) density, (b) cribriform growth for GP 4, and (c) tumor morphology. Scale bar $=900 \mu \mathrm{m}$ 
a Registered histopathology

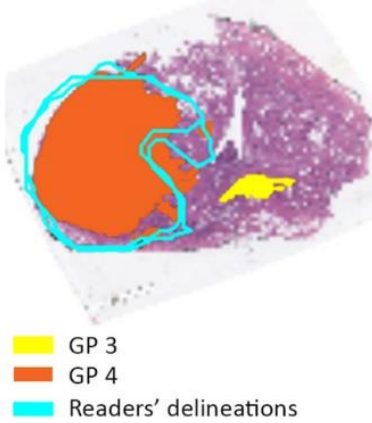

Readers' delineations

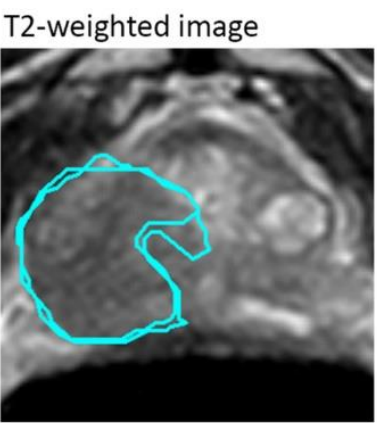

T2 map

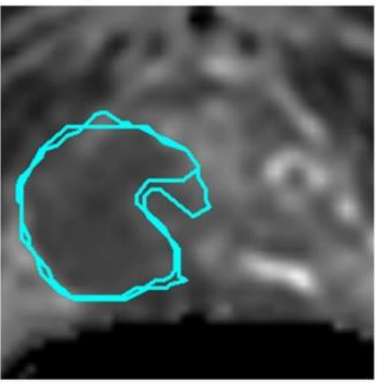

b Registered histopathology T2-weighted image

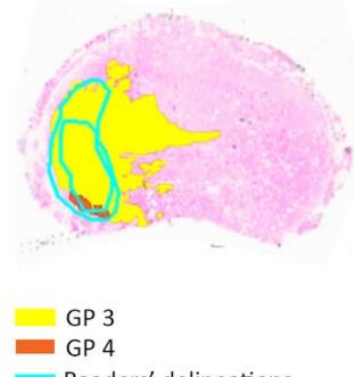

Readers' delineations

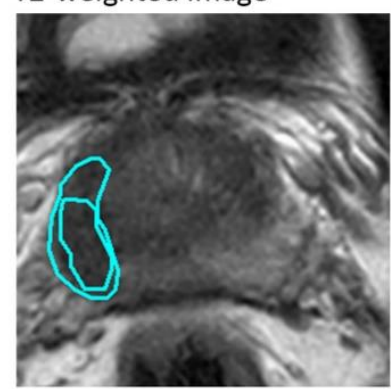

T2 map

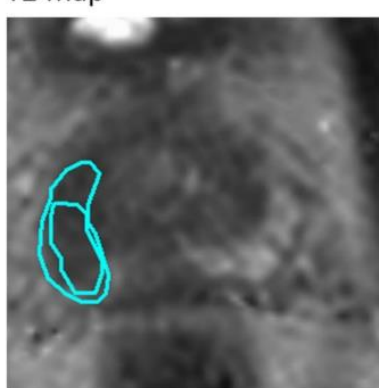

DWI image $\left(b=1000 \mathrm{~s} / \mathrm{mm}^{2}\right)$ DCE image at $90 \mathrm{~s}$

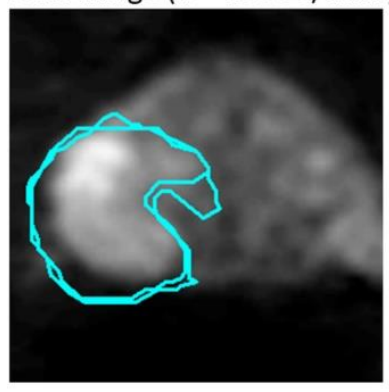

ADC map

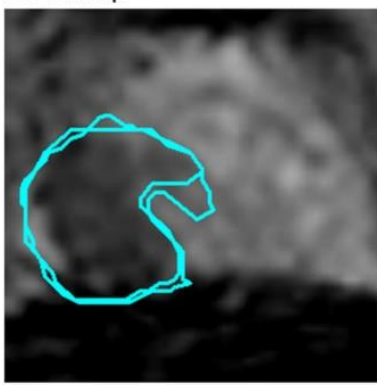

DWI image $\left(b=1000 \mathrm{~s} / \mathrm{mm}^{2}\right)$ DCE image at $90 \mathrm{~s}$

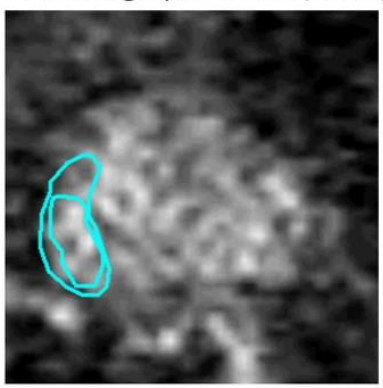

ADC map

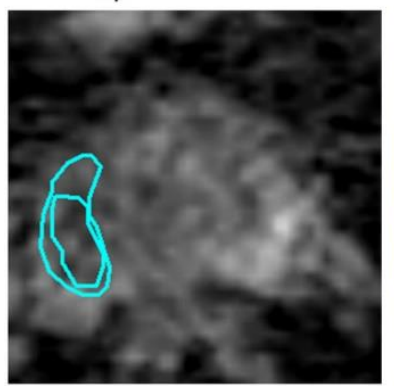

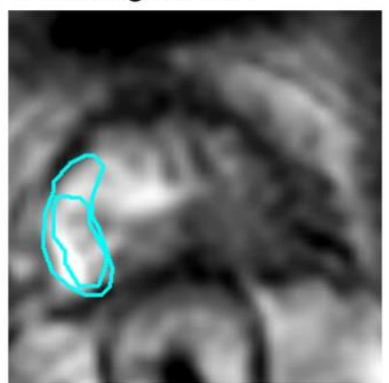

$\mathrm{K}^{\text {trans }}$ map

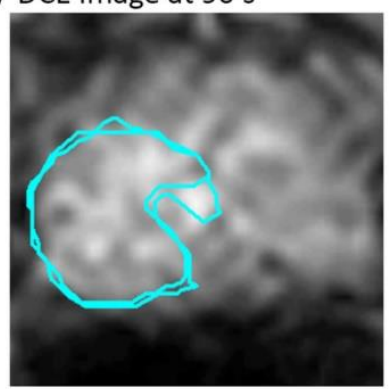

$\mathrm{K}^{\text {trans }}$ map
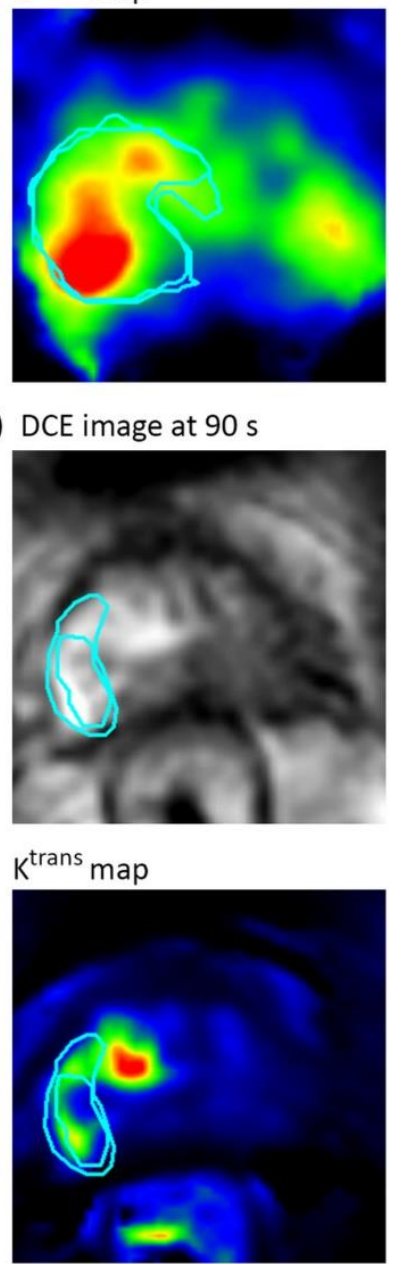

Two examples of patients with GP segmentations on the registered histopathology slice and the delineations of readers shown on the corresponding axial mpMRI images. (a) An example of two lesions on the histopathology slice, one was visible and almost completely delineated, and the other one invisible on mpMRI for the readers. (b) An example of a visible lesion that was partially delineated by the readers. For DWI an image of $b$-value of $1000 \mathrm{~s} / \mathrm{mm}^{2}$ is shown, whereas for DCE one of the dynamic scans at $90 \mathrm{sec}$ is shown. The $T_{2}$ maps are scaled between 0 and $300 \mathrm{msec}$, the ADC maps are scaled between 0 and $2.4 * 10^{-3} \mathrm{~mm}^{2} / \mathrm{s}$, and $\mathrm{K}^{\text {trans }}$ maps are scaled between 0 and 0.8 $\min ^{-1}$. 
Figure 4
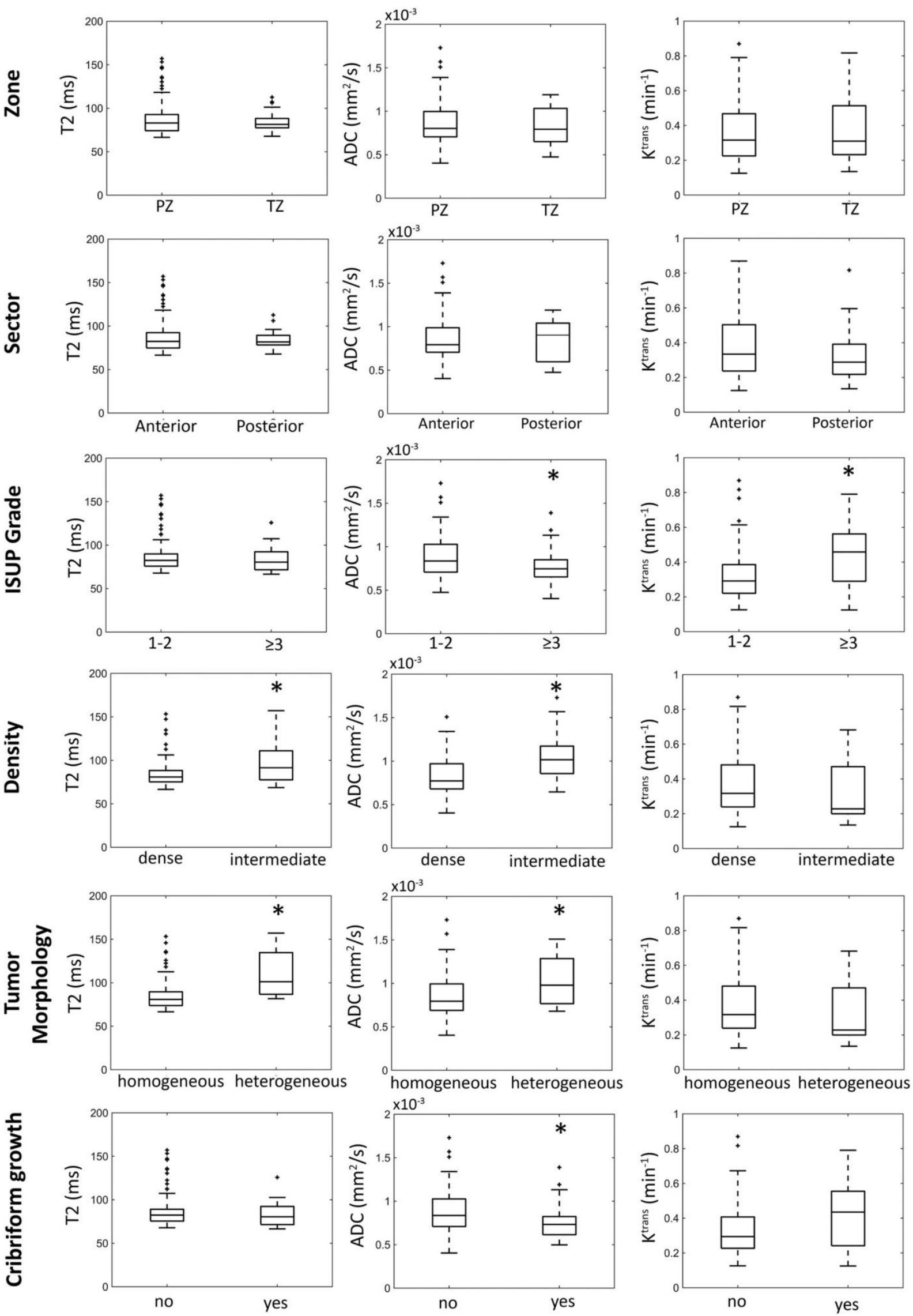
Imaging characteristics of all regions (median $\mathrm{T}_{2}$, median $\mathrm{ADC}$, and median $\mathrm{K}^{\text {trans }}$ ) for location and histopathology features. Asterisks indicate statistical significance between the two groups $(P<0.05)$.

Figure 5

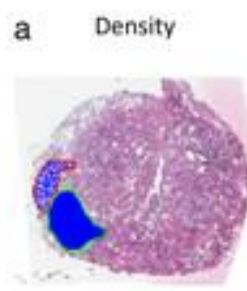

b

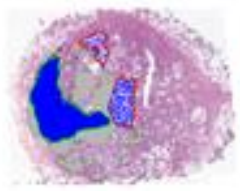

c

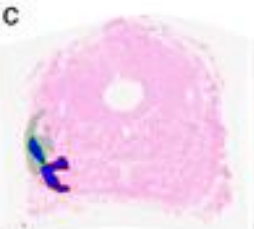

d
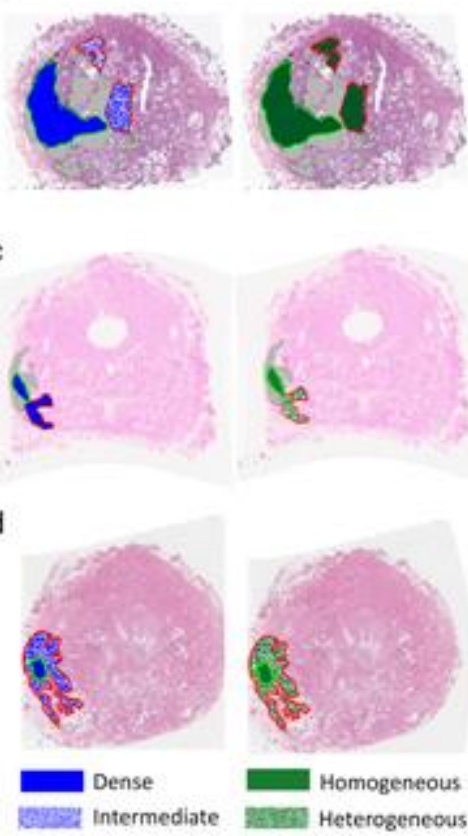
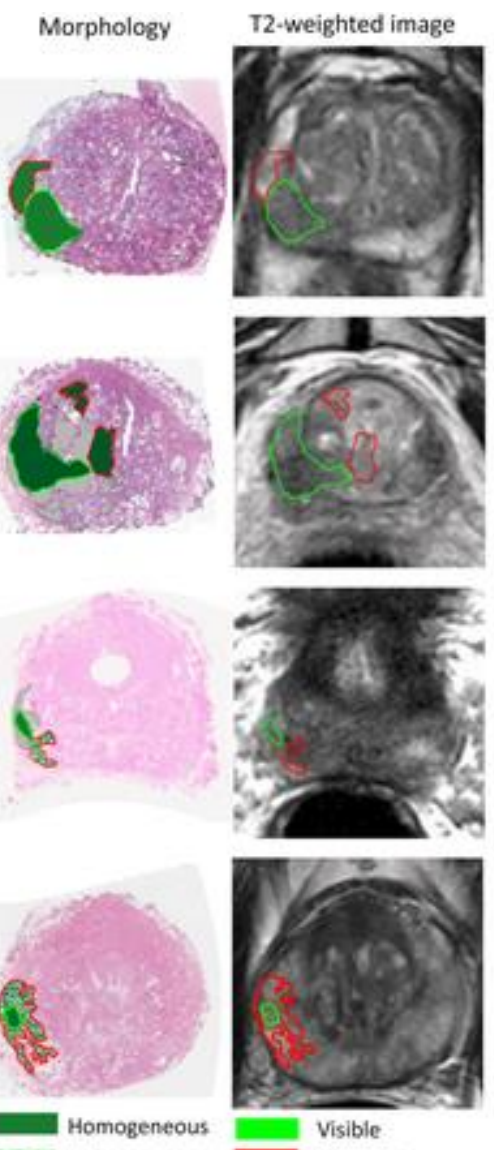

$A D C$ map
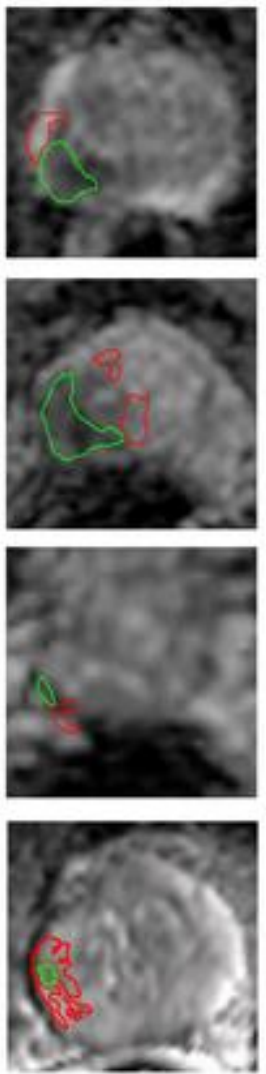

$K^{\text {trms }}$ map
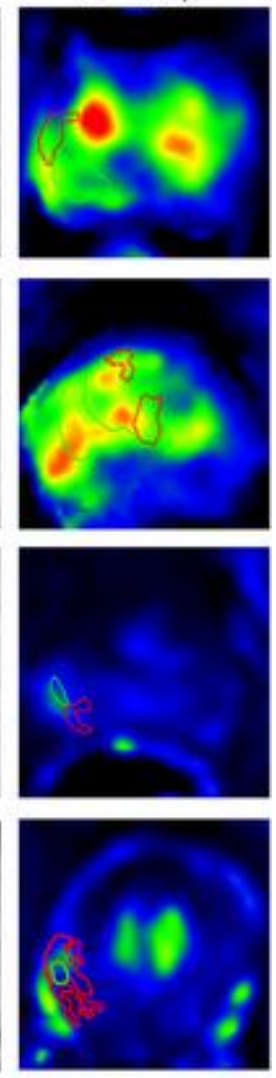

Inconsistently delineated

The histopathology features and imaging characteristics of visible (green delineation) and invisible regions (red delineation) are illustrated in four patients. Each row represents one patient. The ADC maps are scaled between 0 and $2.4 * 10^{-3} \mathrm{~mm}^{2} / \mathrm{s}$, and $K^{\text {trans }}$ maps are scaled between 0 and $0.8 \mathrm{~min}$

${ }^{1}$. (a) A patient with ISUP grade 4 lesion with homogenous morphology and cribriform growth located in PZ. The invisible region had intermediate density, whereas the visible region was dense. (b) A patient with ISUP grade 4 lesion. The visible region was dense, with cribriform growth and located in $\mathrm{PZ}$, whereas the invisible region had intermediate morphology, without cribriform growth and located in TZ. (c) A patient with ISUP grade 2, dense lesion in PZ. The visible region had homogeneous morphology, whereas the invisible region was heterogeneous. (d) A patient with ISUP grade 2 lesion in PZ. The visible region was dense and had homogenous morphology, whereas the invisible region had intermediate density and heterogeneous morphology. 
Figure S1
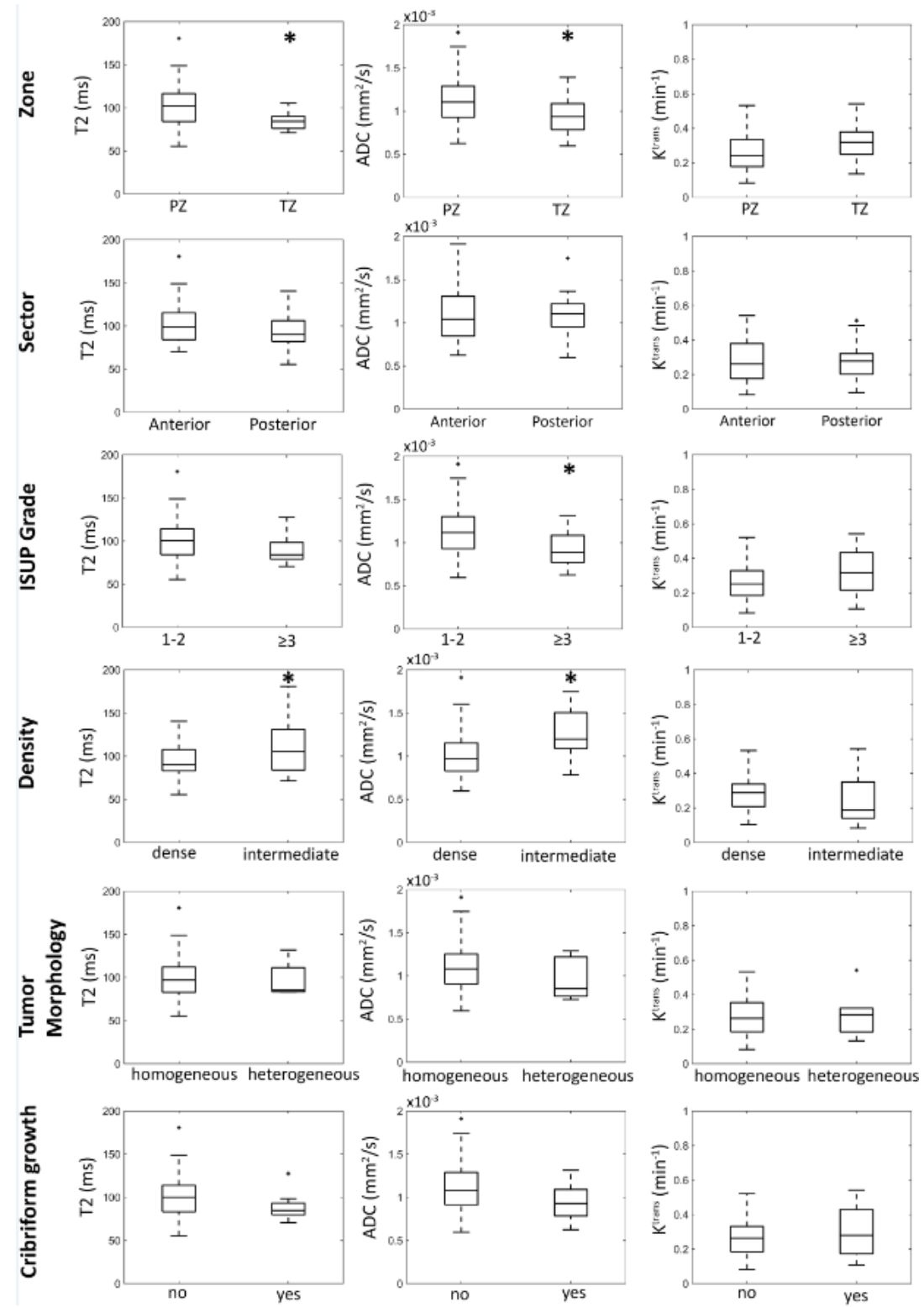

Imaging characteristics of all lesions (median T2, median ADC, and median $\mathrm{K}^{\text {trans }}$ ) for location and histopathology features. Asterisks indicate statistical significance between the two groups $(p<0.05)$. 


\section{Supporting information}

\section{Assessment of qMRI performance}

In this study, quantitative MRI was acquired at three systems. Prior to start of the patient study, the MR protocols were checked for consistency using calibration phantoms. For T2 the Eurospin II test object 5 (Diagnostic Sonar LTD, Livingston, Scotland) was used, whereas for ADC an ice-water phantom was used [1]. As there is no direct way to validate $K^{\text {trans }}$ we checked two aspects that are important in the analysis pipeline with the Eurospin II phantom: accuracy of baseline T1 mapping and stability of DCE signal during the acquisition. The accuracy of T2, ADC, and T1 was expressed as the systematic error Systematic error $=\frac{\bar{X}-X_{\text {true }}}{X_{\text {true }}} \cdot 100 \%$

(1)

Where $X_{\text {true }}$ is the true value known for the sample in the phantom and $\bar{X}$ the measured value averaged over voxels inside a region. Systematic error was calculated per sample in the phantom. Median and range were calculated.

Table 1 Systematic error for T2, ADC, and T measured on the three different systems. For T2 and T1 median and range are reported for the twelve samples in the phantom. For ADC only one sample was available. Values for the center slice were used.

\begin{tabular}{llll}
\hline Systematic Error (\%) & System A & System B & System C \\
\hline & Median (range) & Median (range) & Median (range) \\
T2 & $-7 \%(-11$ to -1$)$ & $2 \%(-2$ to 8$)$ & $-2 \%(-7$ to 2$)$ \\
ADC & $4 \%$ & $3 \%$ & $-1 \%$ \\
T1 & $-7 \%(-16$ to -7$)$ & $-14 \%(-21$ to -3$)$ & $-9 \%(-21$ to 13$)$ \\
\hline
\end{tabular}

To estimate the stability of the DCE signal, the coefficient of variation was calculated from the signal intensities in an ROI during the acquisition. The CV was similar for the three institutes with an overall average CV of $1.5 \pm 0.6 \%$.

\section{Assessment of registration errors}

We estimated the accuracy of the registration between histopathology and the T2-weighted MRI by measuring the Euclidean distance between landmarks placed in the histopathology and T2-weighed slices. For this we selected one slide per patient and asked two independent observers with different levels of experience in image-histopathology registration to place at least three landmarks. These were different landmarks as used for the registration. We found an average of $2.5 \pm 1.2 \mathrm{~mm}$ landmark distance for an inexperienced observer and $1.8 \pm 0.8 \mathrm{~mm}$ for the experienced observer.

For six patients we estimated the angle between the histopathology and the MRI slices to verify whether the slice-by-slice correspondence as introduced by the mold was correct. We observed a median angle of $3^{\circ}\left(\right.$ range $\left.1^{\circ}-9^{\circ}\right)$. 


\section{References}

[1] Chenevert TL, Galbán CJ, Ivancevic MK, et al. Diffusion coefficient measurement using a temperature-controlled fluid for quality control in multicenter studies. J Magn Reson Imaging 2011; 34: 983-987. 